\title{
Countermeasures of New Urbanization Construction in Jilin Province
}

\author{
Hongying Ji and Di Wang* \\ Economics and Management of Beihua University, Jilin, 132013 \\ 418470072@qq.com, 240334268@qq.com
}

Keywords: Jilin Province; The new urbanization; Constraints; Expenditure; Cultural industries

\begin{abstract}
The new urbanization is a major strategic the Eighteenth National Congress of the Communist Party of China. The New Urbanization in Jilin Province is in the strategic period of accelerating development. Jilin made a lot of achievements in the process of urbanization while there are all sorts of problems. As a major agricultural province and old industrial base of the northeast, Jilin Province has some constraints in the construction of the new urbanization, such as the slow development of tertiary industry, the obvious contradiction between fiscal revenue and expenditure, lack of brand awareness in small towns, lack of new urbanization theory and cognitive systems and etc. We propose corresponding countermeasures in response to the constraints for Jilin Province in order to offer some help.
\end{abstract}

\section{Introduction}

Our current economy has entered a new normal with slower growth. The National Bureau of Statistics data show that in 2015 China's GDP grew by $6.9 \%$ which is the lowest rate in 25 years. Jilin Province has a low growth record of $6.5 \%$ with the economic downward pressure, which means new urbanization construction has become a major driving force for future economic development. Pushing forward the construction of new urbanization with Jilin characteristics can improve the income level of farmers in Jilin Province, accelerate the transformation and upgrading of industrial structure and promote overall social progress with great significance [1].

\section{Situation and Problems of Urbanization Development in Jilin Province}

Situation of Urbanization Development in Jilin Province. Urbanization Development in Jilin Province has experienced rapid development after the founding of the nation (Urban rate was 39.3\% in 1960), fluctuations decrease in the Great Leap Forward, the Cultural Revolution and The Three Years of Natural Disasters (Urban rate was 30.2\% in 1977), the rapid development period after the reform and opening up (Urban rate was $49.66 \%$ in 2000), the slow development of state-owned enterprises reform (Urban rate was $53.36 \%$ in 2011) and the new phase of urbanization since the Eighteenth National Congress of the Communist Party of China [2].

In 2012, the Eighteenth National Congress of the Communist Party officially presented new type urbanization. Jilin Province responded positively to this national policy guidance and gave the high priority of the construction of new urbanization with remarkable achievements. In 2014, the disposable income per permanent residents in urban and rural capita reached 23,217 yuan and 10,780 yuan, which means that it increases of $8.8 \%$ and $10.2 \%$ respectively. The income of urban and rural residents has already grown faster than GDP growth for many years and the gap continued to narrow as in Fig. 1. 


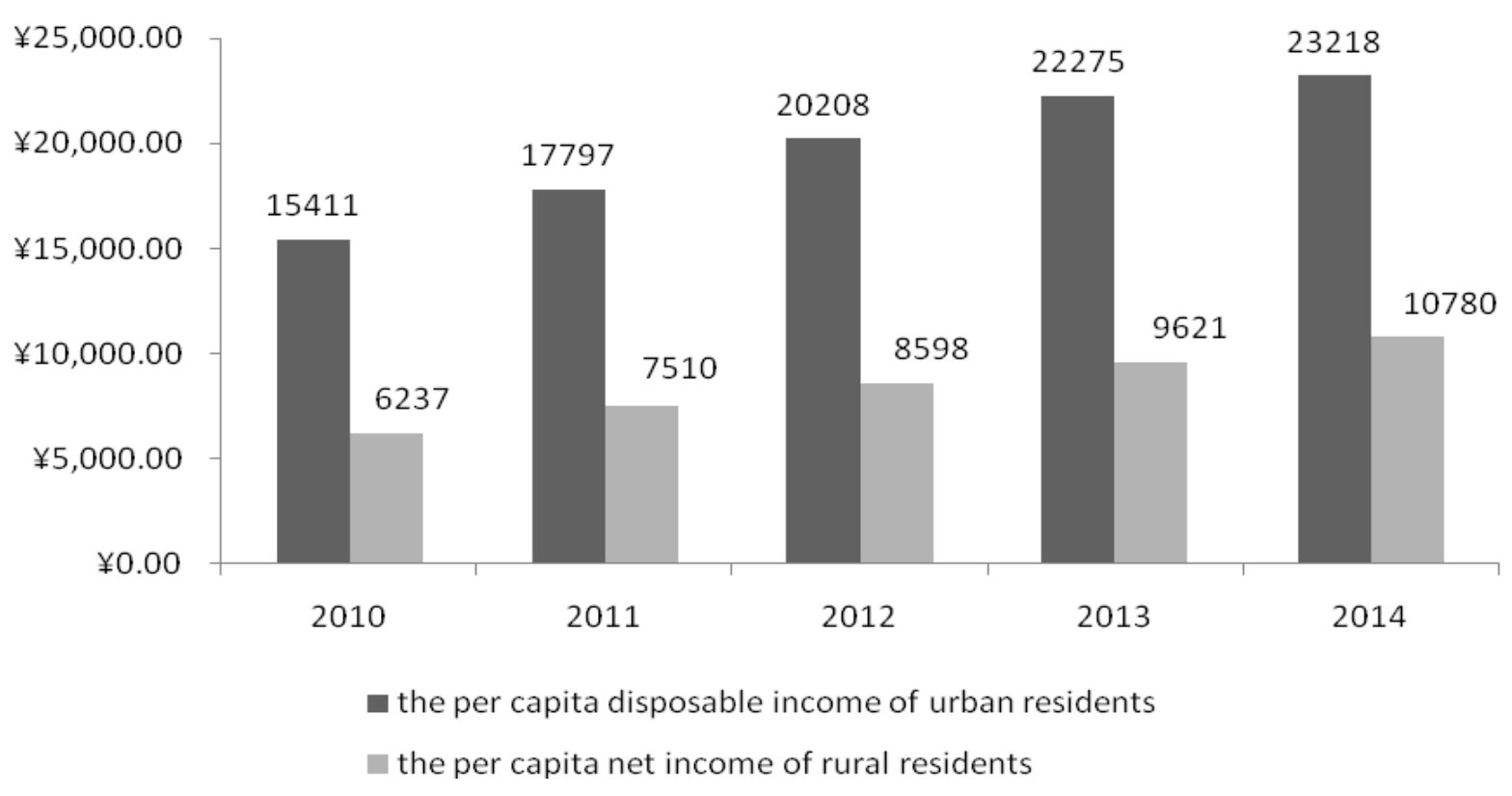

Figure 1. 2010 - 2014 Jilin urban and rural residents' disposable income (Unit: RMB)

Source: Statistical Information Network in Jilin Province March 23, 2015

Source: Bureau of Jilin Province

Problems of Urbanization Development in Jilin Province. In the process of urbanization, Jilin Province has made great achievements for the development of China's urbanization, but there are also some outstanding issues which needs solution in the development process.

Unbalanced Development in the East, the Central and Western. There are nine prefecture-level cities in Jilin province. According to the geographical location and administrative regions, it can be divided into three regions, namely the Eastern Economic Region including Tonghua, Baishan and Yanbian Prefecture, the Central Economic Region including Changchun, Jilin, Liaoyuan and Siping and the Western Economic Region of Baicheng and Songyuan City. In the development of urbanization process, each prefecture-level city area urbanization rate is high, but the overall development of regional urbanization is very uneven. By the end of 2014, the urbanization rate of the Eastern Economic Region is the highest of $62.4 \%$, while the lowest is the Western Economic Region of 33.9\%; the Central Economic Region urbanization rate is $45.5 \%$ at the same time [3].

Lack of Industrial Supporting Capacity. Since the implementation of the revitalization of northeast old industrial bases, Jilin Province Industrial restructuring has made some achievements, but the six high energy-consuming industries in the industrial structure still account for a large share and the emerging industrial strength has not yet formed. Jilin high-tech industry R \& D funding strength is still at a low level while the personnel strength is much lower than the national average. Moreover there is a lower degree of collaboration between industrial regions and towns while the cluster development advantage is not obvious.

Slight Increased in the Urbanization Rate. In recent years, the urbanization rate in Jilin Province is in the middle level which lagged behind compared with the developed provinces. Compared with the three northeastern provinces such as Liaoning Province, there is a lot gap and slight increase. The average growth rate lagged behind the national average, see Table 1. 
Table 1. Urbanization rate in three northeastern provinces and the average growth rate of the nation (Rounded of the rate data)

\begin{tabular}{|c|c|c|c|c|c|c|}
\hline Region & 2014 & 2013 & 2012 & 2011 & 2010 & $\begin{array}{c}\text { Average } \\
\text { Increase }\end{array}$ \\
\hline Jilin & 54.8 & 54.2 & 53.7 & 53.4 & 53.3 & 0.375 \\
\hline $\begin{array}{c}\text { Liaonin } \\
\mathrm{g}\end{array}$ & 67 & 66.4 & 65.6 & 64 & 62.1 & 1.225 \\
\hline $\begin{array}{c}\text { Heilongj } \\
\text { iang }\end{array}$ & 58 & 57.4 & 56.9 & 56.5 & 55.7 & 0.575 \\
\hline Nation & 54.8 & 53.7 & 52.6 & 51.3 & 49.9 & 1.225 \\
\hline
\end{tabular}

Source: National data, the National Bureau of Statistics of People's Republic of China Second, the new urbanization in Jilin Province Construction constraints

\section{Constraints in New Urbanization Construction in Jilin}

Slow Development in the Third Industry. In 2014, the proportion of the structure of the three industries in Jilin Province was 11.0: 52.8: 36.2 and the economic growth rate was 6.8\%, respectively, $55.6 \%$ and $37.6 \%$ [3] which the proportion of secondary industry still dominates. In the second industry, traditional industries take the major proportion. Jilin Province makes the inevitable economic downturn especially after international prices of energy and raw materials and other commodities dropped significantly as well as the traditional industry overcapacity pressure. Currently, agricultural foundation in Jilin Province is deep while the industrialization and modernization process is slow. The third industry develops in a slow speed lacking of characteristics. Compared with the national average level the third industry accounts for the low proportion of GDP [4]. In Jilin Province, the development of cultural industries makes backwardness lacking of distinctive characteristics and brand, which has a big gap with the developed provinces and municipalities.

Obvious Contradiction between Fiscal Revenue and Expenditure and Lack of Supervision. Jilin Province is an old industrial base, which is deeply influenced by the planned economy with the heavy historical burden lacking of competitive ability. Low overall economic development of the province and low proportion in national GDP result in the financial weak of Jilin Province and the obvious contradiction between revenue and expenditure. At the same time the binary tends of financial structure in public spending is still serious and education and medical resources are unequal between urban and rural including greater expenditure spending on economic construction and administration compared public service[5]. In addition there are intermediate links expenditure deductions and waste phenomena, which lacks of effective supervision, management and no comprehensive public and refinement.

Lack of Brand Awareness in the Construction of Small Towns. The Medium-sized cities and towns have focused on brand in the current Urbanization in Jilin Province [6] while the construction of its small towns is lack of brand awareness. Through field investigation, Mao stood Ningjiang Songyuan town, $17 \mathrm{~km}$ from the city center, which is the former Melrose Guo town under the Mongolian Autonomous County. Owned by Melrose Guo Qing Dynasty palace originally having distinctive ethnic characteristics, but its economic development and progress are slow and suffering from continuous population outflow by the lack of brand awareness. Such signs are common everywhere [7]. Ultimately, it is caused by the lack of brand awareness in small cities and towns.

Lack of Cognitive Systems in New Urbanization Theory. Jilin Province is a traditional agricultural province with rural population of 1243.8 million by 2014 , whose overall level of 
education is low. There is a misunderstanding on the concept of from urbanization to the new type urbanization. The first misunderstanding is the confusion of the new type urbanization and urbanization including the conversion from rural to urban population, active area from rural to urban transformation, life style conversion from rural to urban type, etc... The amount of space in the city increasingly expands on a regional scale and the population concentrated in large cities. The second case is that taking the new urbanization as simple as the number increases of cities and towns, urban area expansion and urban residents population increasing which means the replace of the rural town, the destroy the countryside and the development of small towns. The rapid development of small towns in the southeast coastal areas highlighted the effect of urbanization in rural areas [8], but Jilin has essential differences with the southeast coastal areas no matter in natural resources or historical background.

\section{Countermeasures of the New Urbanization Construction in Jilin Province}

Develop the Cultural Industry. Jilin cultural industries should take the road of brand development by work creating "Changbai Mountain brand culture," firstly. Jilin Changbai Mountain brand culture is the iconic symbol of Jilin, which is the leader to cultural characteristics and the brand logo of Jilin characteristic economy. Through the interpersonal communication of "Changbai Mountain Culture", Jilin tries to attract more tourists by means of physical media, communication efforts and ranges of mass media as well as the cultural infrastructure of Changbai Mountain [9]. Secondly, it is important to prominent national characteristics and cultural resources vigorously promote and protect the Manchu culture, Mongolian culture and Korean culture by building the town and villages of ethnic minority autonomous. By creating characteristic cultural enterprises and famous characteristics brands, Jilin should combine with its own resources to develop formal ecological tourist attractions, such as picking garden, music and other farm. Last but not least, Jilin should strengthen the depth of integration between regional characteristics and cultural resources enhance public awareness of cultural heritage protection, improve Jilin characteristics of cultural industries in domestic and international visibility and influence.

Strengthen the Supervision of Expenditure on Public Services. Pay attention to the construction and improvement of urban and rural infrastructure. Jilin Province should strengthen the links between industry and agriculture on basis of the effective guarantee and strengthening on the fundamental status of agriculture in order to improve the overall level of economic development and thus increase fiscal spending on public services. Jilin should increase urban and rural transportation and communication facilities firstly, secondly improve the health and education infrastructure especially in rural area in order to reduce rural-urban gap and finally increase the community infrastructure of residents and enrich material and cultural life and spiritual life so as to achieve the goal of improving the residents' index of well-being.

Strengthen Supervision and Management of Financial Expenditure. The implementation of effective policies requires strict supervision and management so the expenditure should follow the principle of openness and fairness. The government from provincial, municipal to county government should show the details and projects of expenditure. At the same time, the major media should strengthen fiscal expenditure policy on publicity so that residents understand their rights and obligations in order to strengthen the supervision and management of financial expenditure.

Create Brands of Small Towns Combining Eastern-Central-Western Regional Characteristics. The eastern region, rich in cultural heritage, should strengthen the development of cultural industries and tourism industry focusing on the characteristics of its own resources to create brands of small towns. The western region, deeper in the agricultural foundation, can go ecology route processing agricultural products and creating the brands out of the cities and towns. Central region has strategic location and solid in industrial base, which has better historical and cultural heritage foundation, should make use of these advantages continue to develop. The governments of small towns should promote its publicity and take it as the means of its economic development by taking website for festival publicity, etc... By all-round display image of towns, it can improve 
visibility and reputation, enhance the quality of life of residents of small towns, improve urban identity of members in order to achieve economic and social win-win situation.

Focus on Education Development. Pay attention to cultivate high-quality talents. Firstly, take the own advantages of the universities in Jilin Province Universities to cultivate high-quality talents. Secondly, it is important to appreciate the talent from a strategic height, improve the employment mechanism and give strong material support and moral encouragement to the real high-quality talent. Finally, the introduced talent should be given full attention and make them to exert their energy.

Improve the overall quality of the residents in Jilin Province. Jilin Province is a traditional agricultural province, where farmers still serious ideological content and the "Homebody" phenomenon is very prominent. At the same time, the residents in cities have the larger conflict of Migrant Workers [10]. This requires the Jilin Provincial Government to increase investment in education, especially for rural education which can make optimization of rural education resources and to guide the education for rural construction.

New urbanization is characterized by the largest human-centered urbanization. The construction of urbanization and rural urbanization is not to build new high-rise buildings but to improve the quality of life of all residents. Jilin Province should build a comfortable, happy, eco home rely on its own resources and overcome the resistance and constraints in construction of new urbanization.

\section{Acknowledgements}

Jilin Province Association of Social Projects "New Urbanization in Jilin province Restrictive Constraints and Countermeasures" (Project Number: Province-1505-1)

\section{References}

[1] New town planning in Jilin Province [N]. Jilin Daily, 2014-08-07 (9).

[2] H.Y.Ji: Industry and Science \& Technology Forum(2015)No.17,p.27.

[3] Jilin Statistical Yearbook 1949-2014.

[4] M.Hou, W.Kong: Economic Review (2012)No.8,p.96-99.

[5] P.Yin, etc: Economic Geography(2015)No1,p.61-67

[6] J.F.Zhang. New Urbanization Problems Analysis and Countermeasures(MS.Changchun, Jilin University ,China 2015).p.38.

[7] H.Y.Ji: Journal of Yunnan University of Nationalities(2015)No11,p.98-103.

[8] Y.N.Li, etc. Introduction to Chinese new urbanization (Beijing: Chinese Workers Press, 2014).p.4-6.

[9] H.Y.Ji: Journal of Beihua University (2014)No6,p.56-59.

[10] Y.M.Chen: Jianghai Academic Journal (2014) No6,p.61-66. 